\title{
Common Discourse Patterns of Cross-diciplinary Research Article Abstracts in English
}

\author{
Tofan Dwi Hardjanto \\ Universitas Gadjah Mada \\ Email: deha@ugm.ac.id
}

\begin{abstract}
Because of its important role in the advancement of science, attempts have been made to investigate research article abstracts in terms of both their discourse patterning and their linguistic characteristics. This research is an attempt to examine their rhetorical patterning. More specifically, it addresses the questions what common discourse patterns research article abstracts have and whether abstracts from different disciplines show different patterns. The research corpus contained 50 research article abstracts collected from five international journals published in the fields of biology, engineering, linguistics, medicine and physics. The data were analyzed using a four-move abstract structure developed by Hardjanto (1997). The results showed that Moves 1, 3 and 4 were found in most abstracts, and were, therefore, considered as obligatory moves in the abstracts. The most common pattern was found to be a pattern containing all the four moves in the order of 1-2-3-4, especially in abstracts from medicine and linguistics. Another common pattern was a 1-3-4 pattern, found especially in abstracts from biology and physics, whereas abstracts from engineering did not show any preference for a specific pattern even though $40 \%$ of them had a 1-2-3-4 pattern. These results suggest that there is a significant disciplinary variation in English research article abstract patterning.
\end{abstract}

Keywords: abstract, discourse pattern, move, research article

\section{INTRODUCTION}

Today, as "a description or factual summary of the much longer report, and is meant to give the reader an exact and concise knowledge of the full article." (Bhatia, 1993: 78), the abstract has become an inseparable part of the research article. Almost all academic journals, in whatever language they are published, have now required authors to include abstracts in the research articles (RA) they send for publication (Martín, 2003). In the Indonesian context, many, if not all, academic journals require authors to submit two types of abstracts, one in English and another in Indonesian. This tendency results from the improtant role the abstract plays in the advancement of scientific knowledge. Jacks (1961: 410) contends that "it might be said that the body of a paper is written primarily for the advancement of the scientist to make or maintain his reputation and the summary (abstract) for the advancement of science." Moreover, the abstract is often key to the acceptance of a research article for publication in an academic journal or for presentation in a seminar or conference. It is also of crucial importance because it is the abstract together with the title of the article that first of all attracts the reader's attention, so in order to be recognized and accepted by his/her discourse community, the author often depends on it (Hardjanto, 1997: 114). Furthermore, Swales (1990: 179) argues that "readers of RAs are extremely fickle: of those who will read the title, only some will read the abstract, 
and of those who read the abstract only some who will read the article itself."

RA abstracts have an important communicative function. van Dijk (1980: 100-1) suggests that they "indicate an appropriate reading for the text, by expressing the macrostructure of the text as intended by the author, so that correct understanding of the text is possible." Besides, van Dijk adds, they also serve as independent types of discourse. They are "typically discourse-length expression of the macrostructures of a discourse" (van Dijk, 1980: 101). Support for this claim come from Bazerman (1984: 18) who claims that the abstract is basically a representation of the article which is "one further step in turning the article into an object, for the abstract considers the article as a whole and then makes a representation of it." Moreover, the process of writing a research article abstract is an art which demands "the application of extensive reading, thinking, writing, and editing skills" (Cremmins, 1982: 3).

Because of its important role and function, the RA abstract as an independent genre (Lorés, 2004) has attracted many different scholars to investigate not only its linguistic characteristics, but also its discourse structures. In linguistics, Gopnik is probably the first to analyze abstracts in great detail. Working within the framework of transformational-generative grammar, Gopnik identifies three major types of texts: (1) controlled experiment, (2) hypothesis verification, (3) technique-descriptive. These three types of texts are defined in terms of formal criteria, ie., according to the different patterns of syntactic structures which can serve to distinguish among different types of texts. Each type is determined by (1) the occurrence of certain key transformations, (2) the order in which particular transformations occur, (3) the non-occurrence of some transformations, (4) the interrelationships among transformations, and (5) the relationships among the noun phrases and verb phrases which occur in sentences of the text. In other words, each type of text is determined by a set of syntactic structures, either obligatory or optional, which characterize it. Gopnik claims that these three types of texts together with their subtypes are applicable not only to abstracts but also to the whole range of scientific texts, whatever form they take, which I consider as too bold a claim to be pedagogically useful. Furthermore, her analysis fails to take account of the communicative purposes of a text, primarily because each type of text is "not defined in terms of this semantic content [ie. semantic information carried by the structure of the text], but rather in terms of formal criteria" (1972: 53).

In a less detailed study, Graetz (1985) examined, with a pedagogical motivation in mind, the opening and closing lines of 87 abstracts of articles selected at random from 41 scholarly journals. In this study, she was particularly interested in the language rather than the discourse structure of abstracts. Following Widdowson's syntactic-grammatical and semantic-rhetorical categorization (Widdowson, 1979: 101-111), she categorized the introductory sentences of abstracts into nine categories: passive construction, perfect tense, thesis statement in opening sentence, thesis statement delayed until second, third or fourth sentence, allusion to authority, and the remaining four categories being combinations of two or more of the previous ones. As for the concluding lines, she categorized them into two types, each consisting of a number of categories. Type A includes those of which the purpose of the conclusion is to physically conclude the abstract, and Type B those of which the purpose of the conclusion is to leave the reader with some thoughts through suggestion, implication, question, etc.

More interesting to note, perhaps, is the summary she made of the literature on abstract writing in the library science. With respect to the language of abstracts, for example, Graetz (1985: 125) argues:

The abstract is characterized by the use of past tense, third person, passive and the non-use of negatives. It avoids subordinate clauses, uses phrases instead of clauses, words instead of phrases. It avoids abbreviation, jargon, symbols and other language shortcuts which might lead to confusion. It is written in tightly worded sentences, which avoids repetition, meaningless expressions, superlatives, adjectives, illustrations, preliminaries, descriptive details, examples, footnotes. In short it eliminates the redundancy which the skilled reader counts on finding in written 
language and which usually facilitates comprehension.

How far Graetz's conclusions are acceptable is of course open to question. While some of them seem to be supportable, others are doubtful. Swales (1990: 180) considers this statement a little too bold. Kaplan et. al. (1994) found some variations in the use of tenses and voice, some abbreviations and acronyms, and many subordinate clauses in the conference abstracts they investigated. It is not too difficult to find examples contradicting what Graetz claims above. Abstracts have, among others, such characteristics as brevity, compactness and complexity of syntactic structures. However, as Hyland (2000: 65) argues, the brevity of abstracts is conditioned by rhetorical consideration.

Following these two pioneering works on RA abstracts, quite a few studies have been made to investigate RA abstracts not only in terms of their discourse patterning (e.g., Bhatia, 1993; Cross \& Oppenheim, 2006; Hardjanto, 1997; Hyland, 2000; Lorés, 2004; Pho, 2013; Santos, 1996) but also in terms of their linguistic characteristics (e.g., Busch-Lauer, 1995; Pho, 2008; Van Bonn, \& Swales, 2007). Santos (1996), for example, examined both the macro textual organization and the micro linguistic characteristics of RA abstracts. On the basis of his analysis of 90 RA abstracts in applied linguistics, he developed a five-move model of RA abstract patterning, i.e., Situating the research (Move 1), Presenting the research (Move 2), Describing the methodology (Move 3), Summarizing the results (Move 4), dan Discussing the research (Move 5). He found that Moves 2 and 3 were obligatory as they were used in almost all abstracts, whereas Move 4 was used in most abstracts (80\%). Moreover, he found that such linguistic devices as thematization, tenses and voice were used differently in different moves.

This 5-move model was adopted and slightly modified by Pho (2013). Using this modified model, he analyzed 40 RA abstracts in applied linguistics and educational technology. He found that Moves 2 and 3 were used in all the abstracts he studied. However, slightly different from Santos (1996), Pho found that Move 4 was also obligatory as it was used in all the abstracts under investigation-Pho (2013: 33) considers a move an obligatory move if it is used in all abstracts. Pho (2013: 47) argues that this difference may result from the different types of RA abstracts investigated. It is also possible that the difference is caused by a shift in the types of abstracts used in applied linguistics, from a more descriptive type of abstract to a more informative type. Finally, it may be the case that such a discrepancy is a reflecttion of the RA abstract author to "promote their own study by reporting the main findings in the Abstract" (Pho, 2013: 47).

Unlike Santos (1996) and Pho (2013), Hardjanto (1997) developed a four-move model, i.e., Creating a research space (Move 1), Describing research procedure (Move 2), Summarizing principal results (Move 3), and Evaluating results (Move 4). Application of this model to 50 RA abstracts in the fields of electronics, medicine, physics, psychology and sociology indicates that Moves 1 and 3 are obligatory as they were used in almost all cases (98\%), whereas Move 4 was used in most cases ( $86 \%$ ) and Move 2 in only $56 \%$. These findings are somewhat different from those of Pho (2013) and Santos (1996), especially in terms of the description of methodology. In both Santos and Pho, the Describing the methodology move was found to be obligatory in an RA abstract, while in Hardjanto it was not. In fact, the Describing research procedure move in Hardjanto's model was found to be the least commonly used. This discrepancy suggests that RA abstracts in applied linguistics seem to have different rhetorical patterns from those in electronics, medicine, physics, psychology and sociology.

The present research is an attempt to extend Hardjanto's model to new data. It addresses the following two questions: (a) what discourse patterns do abstracts published in English research articles from different disciplines have? and (b) what are the similarities and differences of the discourse patterns of English RA abstracts from different disciplines? Therefore, in response to these questions, this study aims at examining the discourse patterning of English RA abstracts from five different discipline, biology, engineering, linguistics, medicine, and physics. Examination of the abstracts was done using the move-step model proposed and developed by Swales (1981, 1990, 2004). The research investigates the discourse 
patterns of RA abstracts by accounting for the communicative purposes of each of the rhetorical unit of RA abstracts. In addition, it also studies cross-disciplinary variation in the discourse patterning of English RA abstracts.

\section{METHODS}

The corpus for this research consists of $50 \mathrm{RA}$ abstracts published in 2013 in five international journals from five different disciplines, i.e., biology, engineering, linguistics, medicine, and physics. The underlying reason for the selection of these disciplines is the relatively low number of studies of RA abstracts in these disciplines. As for the five journals, they were selected through convenient sampling (Dörnyei, 2007: 98-9). For a journal to be selected, it had to be easily and freely accessible on the Internet; it also had to be indexed in the Web of Science Arts and Humanitties Citation Index (http://ip-science. thomsonreuters.com/mjl/publist sciex.pdf), Web of Science Science Citation Index (http://ipscience.thomsonreuters.com $/ \mathrm{mjl} /$ publist_sciex. pdf) atau Web of Science Social Sciences Citation Index (http://ip-science.thomsonreuters.com/mjl/ publist_ssci.pdf). On the basis of these two criteria, five journals were selected, each representing each discipline: The Plant Cell for biology, Journal of Mechanical Engineering for engineering, Journal of Pragmatics for linguistics, The American Journal of Medicine for medicine, and Proceedings of the National Academy of Sciences for physics.

The selection of the abstracts was also done through convenient sampling. Only abstracts published in primary journals (Landau \& Weiss, 1976) were selected. In addition, only abstracts of experimental research articles (Hill et al., 1982) were selected. Abstracts of theoretical articles and of review articles were ignored. The reason for this was the large proportion given to experimental research articles in the publication of research articles (Hardjanto, 1997: 114). Next, only one abstract was selected, that is, the abstract of the first article published in one edition of the selected journal. If the first article was not an experimental research article, the second article was considered. If it was experimental, then its abstract was selected. Otherwise, the next article was considered, and so on. On the basis of these criteria, ten abstracts were selected from each of the five journals, amounting to 50 abstracts altogether from five journals. For ease of reference and analysis, each abstract was given a number from 01 to 10 , written after the abbreviation of each of the five disciplines, i.e., BIO for biology, ENG for engineering, LIN for linguistics, MED for medicine and PHY for physics. Table 1 below shows the disciplines, total number of words and sentences for each discipline.

After all the abstracts were selected, they were analyzed for their common discourse patterning. As mentioned above, the theoretical framework adopted in this research is Swales' genre analysis $(1981,1990,2004)$. In this framework, the concept of 'move' plays a vital role. Swales (2004: 228-9) defines it as "a discoursal or rhetorical unit that performs a coherent communicative function in a written or spoken discourse". Pho (2009: 17) states that each move has its own communicative purpose, which together contribute to the general purpose of the text. Each move can be realized by one or more steps, but it is possible for a move not to contain a step (Samraj, 2014).

Tabel 1

Disciplines, total number of words and sentences in the corpus

\begin{tabular}{|c|c|c|}
\hline Disciplines & $\begin{array}{l}\text { Total no. of } \\
\text { words }\end{array}$ & $\begin{array}{l}\text { Total no. of } \\
\text { sentences }\end{array}$ \\
\hline Biology & 1,763 & 74 \\
\hline Engineering & 2,023 & 83 \\
\hline Linguistics & 1,797 & 65 \\
\hline Medicine & 2,992 & 114 \\
\hline Physics & 2,010 & 71 \\
\hline Total & 10,585 & 407 \\
\hline Mean & 2117 & 81.4 \\
\hline
\end{tabular}

Moves and steps are functional units and they can be obligatory or optional in a genre. A move or a step is considered obligatory if it occurs regularly within a genre. However, the criteria for determining whether or not a move or step is obligatory are used differently by different scholars. Some consider a move or a step obligatory if it is used in more than $50 \%$ cases; others in $60 \%$ or even $80 \%$ cases. Pho (2013: 33 ) considers a move obligatory if it is used in all cases 
$(100 \%)$. A move used in more than $60 \%$ but less than $100 \%$ is considered prototypical, and that used in less than $60 \%$ is considered optional. Slightly different from Pho (2013), in this research, the cut-off point is $90 \%$ for an obligatory move or step, more than $60 \%$ but less than $90 \%$ for a prototypical move or step, and less than $60 \%$ for an optional move or step.

The identification of a move is important in genre analysis. Swales (2004: 229) contends that the identification of a move and the boundary between moves is based on "a mixed bag of criteria." Some researchers use a bottom-up approach (Pho, 2013: 29-30), i.e., using linguistic characteristics to mark a move and its boundary with other moves. For example, Anderson \& Maclean (1997) identify a conclusion move in RA abstracts on the basis of the use of the present tense and the use of certain nouns and verbs. Other researchers use a top-down approach by which a move is differentiated from other moves on the basis of its communicative function. Pho (2013), for example, uses this approach with the help of a questioning technique. Thus, part of an abstract which answers the question "What is the study about?" is categorized as a Presenting the present research move. The identification of moves in this research follows this top-down approach with an emphasis on the function of the move being identified.

Furthermore, it is necessary to determine the minimal unit of analysis. Contrary to McKinley (1984) who claims that a move can be realized by a single sentence, a group of sentences or even a paragraph, and also to Crookes (1986), Santos (1996), Holmes (1997) and Pho (2013) who consider the sentence as the basic unit of analysis, the present research follows Hardjanto (1997) who counts the clause as the minimal unit of analysis. This is particularly because of the important role the clause plays in verbal communication, as suggested by Winter (1986: 89) that "the signals of grammar and of the grammatical status of the clause are crucial to the understanding and interpretation of the message."

\section{Figure 1}

A four-move model for RA abstracts (Hardjanto, 1997: 116)

\begin{tabular}{|rl|}
\hline Move 1 & Creating a Research Space \\
Step 1 & Establishing the field \\
Step 2 & Preparing for present research \\
Step 3 & Introducing present research \\
Move 2 & Describing Research Procedure \\
Step 1 & Presenting the data \\
Step 2 & Describing the method(s) \\
Move 3 & Summarizing Principal Results \\
& \\
Move 4 & Evaluating Results \\
Step 1 & Drawing conclusion \\
Step 2 & Comparing results \\
Step 3 & Indicating discussion \\
\hline
\end{tabular}

On the basis of these criteria, all the RA abstracts were analyzed for their general discourse patterning. For this purpose, a four-move model was adopted from Hardjanto (1997) to identify the possible moves that the abstracts might have. In this model, Move 1 serves to create a research space by (a) establishing the field, (b) preparing for the present research, and/or (c) introducing the present research. Move 2 serves to describe the research procedures used in the present research by (a) presenting the data, and/or (b) describing the methods used. Move 3 presents a summary of principal results, and Move 4 evaluates the results by (a) drawing conclusions, (b) comparing results, and/or (c) indicating discussion. Figure 1 above summarizes the model. An example of abstracts with a four-move pattern is given below. 
Figure 2

An example of an abstract with a four-move pattern

Total Antioxidant Capacity of Diet and Risk of Heart Failure:

A Population-based Prospective Cohort of Women (MED05)

\section{Move 1}

Few studies have investigated the association between individual antioxidants and risk of heart failure. No previous study has investigated the role of all antioxidants present in diet in relation to heart failure. The aim of this study was to assess the association between total antioxidant capacity of diet, which reflects all of the antioxidant compounds in food and the interactions between them, and the incidence of heart failure among middle-aged and elderly women.

\section{Move 2}

In September 1997, 33,713 women (aged 49-83 years) from the Swedish Mammography Cohort completed a food-frequency questionnaire. Estimates of dietary total antioxidant capacity were based on the Oxygen Radical Absorbance Capacity assay measurements of foods. Women were followed for incident heart failure (hospitalization or mortality of heart failure as the primary cause) through December 2009 using administrative health registries. Cox proportional hazard models were used to calculate relative risks and $95 \%$ confidence intervals.

\section{Move 3}

During 11.3 years of follow-up (394,059 personyears), we identified 894 incident cases of heart failure. Total antioxidant capacity of diet was inversely associated with heart failure (the multivariable-adjusted relative risk in the highest quintile compared with the lowest was 0.58 [95\% confidence interval, 0.47-0.72; P for trend $<.001$ ]). The crude incidence rate was $18 / 10,000$ person-years in the highest quintile versus $34 / 10,000$ person-years in the lowest quintile.

\section{Move 4}

The total antioxidant capacity of diet, an estimate reflecting all antioxidants in diet, was associated with lower risk of heart failure. These results indicate that a healthful diet high in antioxidants may help prevent heart failure.

\section{RESULTS AND DISCUSSION}

Based on the four-move model above, the abstracts were analyzed for their general discourse structuring. Table 2 below summarizes the results of this analysis.

Tabel 2

Frequency distribution (\%) of moves across five disciplines

\begin{tabular}{lcrrr}
\hline Disciplines & $\begin{array}{c}\text { Move 1 } \\
(\%)\end{array}$ & $\begin{array}{c}\text { Move 2 } \\
(\mathbf{\%})\end{array}$ & $\begin{array}{c}\text { Move 3 } \\
(\mathbf{\%})\end{array}$ & $\begin{array}{c}\text { Move 4 } \\
(\mathbf{\%})\end{array}$ \\
\hline Biology & 100 & 20 & 100 & 100 \\
Engineering & 100 & 80 & 90 & 50 \\
Linguistics & 100 & 80 & 80 & 100 \\
Medicine & 100 & 100 & 100 & 100 \\
Physics & 100 & 50 & 100 & 100 \\
\hline \multicolumn{1}{c}{ Mean } & $\mathbf{1 0 0}$ & $\mathbf{6 6}$ & $\mathbf{9 4}$ & $\mathbf{9 0}$ \\
\hline
\end{tabular}

The table above shows that not all abstracts have four obligatory moves. All abstracts contain Move 1 Creating a research space, almost all (94\%) have Move 3 Summarizing principal results, and most (90\%) use Move 4 Evaluating results. However, Move 2 Describing research procedure was used in only $66 \%$ of the RA abstracts in the corpus. This suggests that Moves 1, 3, and 4 could be considered as obligatory moves in the abstracts whereas Move 2 belong to the prototypical type as it was found in only $66 \%$ of all the abstracts. The obligatoriness of Moves 1, 3 and 4 may be attributed to the important functions these three moves have for the reader. Move 1 serves to provide the reader with background information or context in which the research is carried out. This moves provides an early orientation to the main purpose or concern of the research. This early indication of the purpose or concern of the research in turn allows the busy reader, who is nowadays flooded with a sea of information, to select relevant information before finally deciding whether or not $\mathrm{s} /$ he reads the article. The examples below illustrate the use of Move 1 in RA abstracts. (Double slashes in the examples indicate step boundary and superscripted number indicating sentence numbers for ease of reference.) While in (2) the authors directly 
present the purpose of their research, in both (1) and (5) the authors start with the establishment of the field, followed by the statement of the research purpose, and in (3) in addition to the establishment of the field by indicating the importance of the research topic, and the introduction of the research purpose, the authors also feels the need to prepare for their research by presenting a gap indication in sentence 2. Slightly differently from the previous examples, in (4), the authors start a research gap indication, i.e., the inconsistent results of previous studies evaluating the association of cardiovascular disease and vascular risk factors with restless legs syndrome, before stating their research purpose.

(1) ${ }^{1}$ The maize (Zea mays) B centromere is composed of B centromere-specific repeats $(\mathrm{ZmBs})$, centromere-specific satellite repeats (CentC), and centromeric retrotransposons of maize (CRM). // ${ }^{2}$ Here we describe a newly formed $\mathrm{B}$ centromere in maize, which has lost CentC sequences and has dramatically reduced $\mathrm{CRM}$ and $\mathrm{ZmBs}$ sequences, but still retains the molecular features of functional centromeres, such as $\mathrm{CENH} 3$, H2A phosphorylation at Thr-133, H3 phosphorylation at Ser-10, and Thr-3 immunostaining signals. (BIO06M1)

(2) ${ }^{1}$ This work studies the influence of high-frequency excitation of a cutting tool during end milling of workpieces made of difficult-to-cut metallic alloys. (ENG05M1)

(3) ${ }^{1}$ Recently, some studies have revealed that facial gestures can play an important role in teasing out the meaning of interrogative sentence types in a particular language (0175 and 0025; among others). $/ /{ }^{2}$ However, less is known about potential cross-linguistic differences. // ${ }^{3}$ This paper investigates the interaction between facial gestures and intonation in the distinction between information-seeking and incredulity yes/no questions in two languages (i.e., Catalan and Dutch) which use different prosodic strategies to express the distinction between these two types of interrogatives. (LIN03M1)
(4) 1 Previous studies evaluating the association of cardiovascular disease and vascular risk factors with restless legs syndrome showed inconsistent results, especially for the potential relation between various vascular risk factors and restless legs syndrome. $/ /{ }^{2} \mathrm{We}$ therefore aimed to analyze the relationships between vascular risk factors, prevalent cardiovascular disease, and restless legs syndrome. (MED02M1)

(5) ${ }^{1}$ From our daily life we are familiar with hexagonal ice, but at very low temperature ice can exist in a different structure - that of cubic ice. // ${ }^{2}$ Seeking to unravel the enigmatic relationship between these two low-pressure phases, we examined their formation on a $\mathrm{Pt}(111)$ substrate at low temperatures with scanning tunneling microscopy and atomic force microscopy. (PHY08M1)

If the reader is intrigued enough by the statements made in Move $1, \mathrm{~s} /$ he might proceed and find in Move 3 a summary of the research findings. This move contains important information that s/ he might need. Examples (6)-(10) below illustrate the use of this move.

(6) ${ }^{1} \mathrm{Anti}-\mathrm{CENH} 3$ chromatin immunoprecipitation sequencing revealed that a $723-\mathrm{kb}$ region from the short arm of chromosome 9 (9S) was involved in the formation of the new centromere. ${ }^{2}$ The $723-\mathrm{kb}$ region, which is gene poor and enriched for transposons, contains two abundant DNA motifs. Genes in the new centromere region are still transcribed. ${ }^{3}$ The original 723-kb region showed a higher DNA methylation level compared with native centromeres but was not significantly changed when it was involved in new centromere formation. (BIO06M3)

(7) ${ }^{1}$ Measurement results have confirmed that excitation of a specific tool mode is a prerequisite for achieving maximal efficiency of the vibration milling process. ${ }^{2}$ Statistical analysis of the 
collected roughness measurement data identified factors that most significantly contribute to the improved surface finish of the workpieces. (ENG05M3)

(8) ${ }^{1}$ The results reveal that there is a contrast between Dutch and Catalan listeners in the perceptual processing of these sentences. ${ }^{2}$ While Dutch participants rely more on intonational differences, Catalan participants use the facial expression cues to a greater extent. (LIN03M3)

(9) ${ }^{1}$ Of the 30,262 participants (mean age: 63.6 years), $3624(12.0 \%)$ reported restless legs syndrome. ${ }^{2}$ In multivariable-adjusted models, BMI (odds ratio [OR] for $\mathrm{BMI} \geq 35 \mathrm{~kg}$, $1.35 ; 95 \%$ confidence interval [CI], 1.17-1.56), diabetes (OR, 1.19; 95\% CI, 1.04-1.35), hypercholesterolemia (OR, 1.17; 95\% CI, 1.09-1.26), smoking status (OR for $\geq 15$ cigarettes/day, 1.41; 95\% CI, 1.19-1.66), and exercise (OR for exercise $\geq 4$ times/week, $0.84 ; 95 \%$ CI, 0.74-0.95) were associated with restless legs syndrome prevalence. ${ }^{3} \mathrm{We}$ found no association between prevalent cardiovascular disease (major cardiovascular disease, myocardial infarction, and stroke) and restless legs syndrome prevalence. ${ }^{4}$ Women who underwent coronary revascularization had a multivariable-adjusted OR of 1.39 (1.10-1.77) for restless legs syndrome. (MED02M3)

(10) ${ }^{1}$ We discovered that during subsequent growth, domain boundaries are replaced by growth spirals around screw dislocations, and that the nature of these spirals determines whether ice adopts the cubic or the hexagonal structure. ${ }^{2}$ Initially, most of these spirals are single, i.e., they host a screw dislocation with a Burgers vector connecting neighboring molecular planes, and produce cubic ice. ${ }^{3}$ Films thicker than $\sim 20 \mathrm{~nm}$, however, are dominated by double spirals. (PHY08M3)
Then, in Move 4, the reader can find the conclusions of the research as shown in the examples below. $\mathrm{S} / \mathrm{he}$ can evaluate the relevance of the conclusions presented in this move to her/his own needs. This is probably why the three moves were used in almost all the abstracts in the corpus.

(11) ${ }^{1}$ Our results indicate that functional centromeres may be formed without the known centromere-specific sequences, yet the maintenance of a high DNA methylation level seems to be crucial for the proper function of a new centromere. (BIO06M4)

(12) It is demonstrated that high-frequency vibrations superimposed onto the continuous movement of the tool lead to milling process stabilization with superior surface finish in comparison to conventional machining.(ENG05M4)

(13) ${ }^{1}$ All in all, the results show that both languages express pragmatic contrasts both at the intonation and facial expression levels, and native speakers are highly sensitive to the relative weight of these cues at the perceptual level. (LIN03M4)

(14) ${ }^{1}$ In this large cohort of female health professionals, various vascular risk factors are associated with the prevalence of restless legs syndrome. ${ }^{2}$ We could not confirm the results of previous reports indicating an association between prevalent cardiovascular disease and restless legs syndrome. (MED02M4)

(15) ${ }^{1}$ Their abundance is surprising because they require a Burgers vector spanning two molecular-layer spacings, distorting the crystal lattice to a larger extent. ${ }^{2} \mathrm{We}$ propose that these double spirals grow at the expense of the initially more common single spirals for an energetic reason: they produce hexagonal ice. (PHY08M4)

It was found in the corpus that three abstracts did not contain Move 3, one from engineering (ENG08) and two from linguistics (LIN01 and LIN07). It was also found that five abstracts did not contain Move 4, all from engineering (ENG01, 
ENG06-09). As regards Move 2, 17 abstracts did not have it, eight from biology (BIO01-06, BIO08 and BIO10), five from physics (PHY0102, PHY05-06 and PHY10), two each from linguistics (LIN01 and LIN05) and engineering (ENG01 and ENG10). The low occurrence of Move 2 in RA abstracts from biology and physics may be attributable to the policy adopted by the journals in the two disciplines. In both The Plant Cell journal from which the biology abstracts were taken and the Proceedings of the National Academy of Sciences from which the physics abstracts were taken, the Method section was found as the last section after the Introduction, Results and Discussion sections. This seems to support the claim that in some dsiciplines, especially in the (hard) sciences, the Methods section of a research articleis downgraded. Swales (1990), for example, reported the findings of Huckin (1987) who argued that the Methods section of research articles in biomedicine is downgraded to such an extent that it was not only positioned as the last section in the articles but also printed in such a small font size that a magnifying glass is needed to read it. Besides, Heslot (1982: 86) also reported that in research articles from chemistry the Methods section "is often given separately after the text proper, with a different size of print."

Table 2 above also indicate variations in terms of the occurrences of the four moves in the abstracts from the five disciplines under investigation. As can be seen, all abstracts from medicine contain Moves 1-4. This means that in this discipline the four moves are obligatory. This may be due to the fact that all the abstracts in The American Journal of Medicine can be categorized as structured abstracts (Bayley \& Eldredge, 2003; Hartley \& Benjamin, 1998). All abstracts in this journal is composed of background, methods, results and conclusions. This is why all the abstracts from medicine have Moves 1-4. This does not apply to all the abstrcats from the other four disciplines because abstracts from these disciplines mostly belong to informative abstracts which put more emphasis on research results. The next discipline which employs the four moves relatively frequently is linguistics with an average frequency of $90 \%$, followed by engineering ( $85 \%$ ), biology (80\% and physics $(80 \%)$.

Even though in general Moves 1 and 2 and 3 were found to be obligatory in all the RA abstracts, it does not mean that the most common pattern is the 1-3-4 move pattern. Closer examination shows that this pattern was used in $32 \%$, slightly less frequently than the 1-2-3-4 move pattern (50\%) where all the four moves were used in an abstract. As mentioned earlier, medicine ranks first in the use of this pattern $(100 \%)$. As can be seen in Table 3 below, the 1-2-3-4 move pattern is also commonly used in abstracts from linguistics $(60 \%)$, followed by engineering (40\%), physics (30\%) and biology $(20 \%)$. This finding seems to suggest that abstracts from medicine and linguistics tend to have the 1-2-3-4 move pattern whereas those from biology and physics commonly have the 1-3-4 pattern. As for abstracts from engineering, they do not seem to show any preference for a specific pattern. Only $40 \%$ of RA abstracts from this discipline have the 1-2-3-4 move pattern, and half of the abstrcats have other patterns.

Tabel 3

Common discourse patterns of RA abstracts across five diciplines

\begin{tabular}{lrrr}
\hline Disciplines & $\begin{array}{c}\text { 1-2-3-4 } \\
\text { Pattern } \\
(\%)\end{array}$ & $\begin{array}{c}\text { 1-3-4 } \\
\text { Pattern } \\
(\%)\end{array}$ & $\begin{array}{c}\text { Other } \\
\text { Patterns } \\
(\%)\end{array}$ \\
\hline Biology & 20 & 80 & - \\
Engineering & 40 & 10 & 50 \\
Linguistics & 60 & 10 & 30 \\
Medicine & 100 & - & - \\
Physics & 30 & 50 & 10 \\
\hline \multicolumn{1}{c}{ Mean } & $\mathbf{5 0}$ & $\mathbf{3 2}$ & $\mathbf{1 8}$ \\
\hline
\end{tabular}

Table 4 below shows the frequency distribution of steps (S) in each of the four moves found in the RA abstracts from the five disciplines. 
Tabel 4

frequency distribution of steps in each move

\begin{tabular}{lrrrrrrrrr}
\hline \multirow{2}{*}{ Disciplines } & \multicolumn{3}{c}{$\begin{array}{c}\text { Move 1 } \\
(\%)\end{array}$} & \multicolumn{2}{c}{$\begin{array}{c}\text { Move 2 } \\
(\%)\end{array}$} & $\begin{array}{c}\text { Move 3 } \\
(\%)\end{array}$ & \multicolumn{2}{c}{$\begin{array}{c}\text { Move 4 } \\
(\%)\end{array}$} \\
\cline { 2 - 11 } & S1 & S2 & S3 & S1 & S2 & & S1 & S2 & S3 \\
\hline Biology & 100 & 30 & 100 & 0 & 20 & 100 & 80 & 10 & 10 \\
Engineering & 80 & 10 & 90 & 0 & 80 & 90 & 50 & 0 & 0 \\
Linguistics & 40 & 10 & 90 & 20 & 70 & 80 & 80 & 20 & 10 \\
Medicine & 60 & 60 & 80 & 60 & 80 & 100 & 100 & 10 & 0 \\
Physics & 90 & 70 & 100 & 0 & 30 & 100 & 90 & 30 & 0 \\
\hline \multicolumn{1}{c}{ Mean } & $\mathbf{7 4}$ & $\mathbf{3 6}$ & $\mathbf{9 2}$ & $\mathbf{1 6}$ & $\mathbf{5 6}$ & $\mathbf{9 4}$ & $\mathbf{8 0}$ & $\mathbf{1 4}$ & $\mathbf{4}$ \\
\hline
\end{tabular}

The table shows that Step 3 Introducing present research of Move 1 is used in almost all abstracts (92\%). It seems that it is this step that make Move 1 obligatory in an abstract. It is interesting to note that all RA abstracts from biology and physics contained this step, whereas in linguistics and engineering it was used in most abstracts (90\%). However, although all RA abstracts from medicine used Move 1, it turns out that the use of Step 3 in this move is not dominant. As a matter of fact, this step was found to be less frequently used in this discipline than in the other four disciplines. In addition to Step 3, Step 1 Establishing the field also seems to be used fairly frequently (74\%) in Move 1 . While Step 3 introduces the main purpose of the research, Step 1 presents important background information.

Next, Move 2 is commonly realized with the use of Step 2, in which the research methods used is briefly described. As can be seen from the table above, in biology and physics, the use of this step is very low ( $20 \%$ and $30 \%$ respectively). As discussed earlier, this is probably attributable to the downgrading of the methods section in these two disciplines. On the contrary, in engineering, linguistics and medicine, research methods seem to play such an important role that they need to be briefly described. Turning now to Move 3, no specific step was used in this move. The table shows that almost all abstracts use this move. This suggests that it is obligatory for an abstract to present a brief summary of principal research results to make it informative. Busy readership perhaps only need the RA abstract for the research purposes, and does not need to waste their time and energy to read the full article.

Finally, Move 4, where evaluation of principal research results presented in Move 3 can be given, is mostly realized by the use of Step 1 Drawing conclusion. Here conclusions that can be drawn from the research are presented. Conclusions and suggestion presented here indicate relevance to the broader research area. This is important, especially for those working on the same or related topics as then the significance of the research can be related to the reader's interest and its contribution to the wider research area. Any indication through conclusions and suggestions that the abstract is relevant will motivate the reader to read the full article. Thus, an abstract serves as an early indication of the content of the article and motivates the reader to read the article. Furthermore, Table 4 also shows that most RA abstracts ( $80 \%$ or more) from biology, linguistics, medicine and physics use Step 1, while only half of the abstracts from engineering use this step. This seems to suggest that presenting conclusions is not necessary in engineering RA abstracts.

\section{CONCLUSION}

Overall, the investigation of the rhetorical organization of RA abstracts from five disciplines, biology, engineering, linguistics, medicine and physics, has shown that RA abstracts are rhetorically divided into a number of sections which are called moves, each of which has its own communicative purpose. The results suggest that in general RA abstracts consist of three obligatory 
moves: Move 1: Creating a research space, Move 3: Summarizing principal results, and Move 4: Evaluating results.

This finding is consistent with that of Hardjanto (1997) and Santos (1996). In these two studies The Creating a research space move, or the Presenting the research move in Santos, was used in almost all of the RA abstracts in their corpora. As a result, it can be regarded as an obligotory move. Likewise, Pho (2013) also found that his Presenting the research move was used in all the abstracts in his corpus. Moreover, the obligatoriness of the third move Summarizing principal results supports Hardjanto (1997) and Pho (2013), who found such a move in all their RA abstracts. However, this is slightly different from Santos (1996) in which this move was found in $80 \%$ of the abstracts he studied.

Likewise, the study is also somewhat different from both Pho (2008; 2013) and Santos (1996), especially in terms of the use of the Describing research procedure move, which is equivalent to the Describing the methodology move in their models. They found that this move was obligatory in the RA abstracts they examined, but in this study it was found to be the least commonly used. This difference might be due to the different disciplines under investigation. As mentioned earlier, Santos (1996) investigated RA abstracts in linguistics and Pho (2013) in applied linguistics and educational technology, whereas the present research examined RA abstracts in biology, engineering, linguistics, medicine and physics. Even in Linguistics the methodology move was found in only $80 \%$ of all RA abstracts; thus it can be regarded as a prototypical move, not an obligatory move. Alternatively, another reason underlying the difference is perhaps the different units of analysis used. While in Pho and Santos the basic unit of analysis was the sentence, in this study it was the clause. Even though this research is different from Pho and Santos in terms of the realization of the methodology move, it supports Hardjanto (1997), who found that only $56 \%$ of RA abstracts in his corpus contain Move 2: Describing research procedure.

Furthermore, the present study is also different from Hardjanto (1997), Pho (2013) and Santos (1996) in terms of the realization of the evaluation of research results move. They categorized this move as a prototypical move as it was found in $86 \%$ of all RA abstracts in Hardjanto, $75 \%$ in Pho and $60 \%$ in Santos, whereas in this research it can be categorized as an obligatory move as it was found in $90 \%$ of all RA abstracts.

The findings of this research suggest that although Moves 1, 3 and 4 were found in almost all abstracts and thus were considered obligatory moves, it does not mean that most abstracts have the 1-3- 4 move pattern. As a matter of fact, this pattern was found in only $32 \%$ of abstracts in the corpus. It was used less frequently than the 1-2-34 move pattern, which was found in half of all the abstracts in the corpus. This supports Hardjanto (1997) who found the pattern to be used in $46 \%$ while the 1-3-4 move pattern was only used in $34 \%$. Moreover, the 1-2-3-4 move pattern tend to be used in RA abstracts from linguistics and medicine, while the 1-3-4 move pattern in biology and physics. RA abstracts from engineering do no show any specific move pattern even though the 1-2-3-4 pattern was found in $40 \%$ of the abstracts from this discipline.

\section{REFERENCES}

Anderson, K., \& Maclean, J. (1997). A genre analysis study of 80 medical abstracts. Edinburgh WorkingPapersinAppliedLinguistics 8, 1-23.

Bayley, L. \& Eldredge, J. (2003). The structured abstract: An essential tool for researchers. Hypothesis: The Journal of the Research Section of MLA 17(1), 1,11-13.

Bazerman, C. (1984). The writing of scientific nonfiction: contexts, choices, constraints. PRE/ TEXT 5, hal. 39-74.

Bhatia, V.K. (1993). Analyzing Genre: Language Use in Professional Settings. London: Longman.

Bhatia, V.K. (2002). Applied genre analysis: a multiperspective model. Iberica 4, 3-19.

Busch-Lauer, I. (1995). Abstracts in German medical journals: A linguistic analysis. Information Processing \& Management 31(5). 769-76.

Cremmins, E.T. (1982). The Art of Abstracting. Philadelphia: ISI Press.

Crookes, G. (1986). Towards a validated analysis of scientific text structure. Applied Linguistics 7/1, hal. 57-70. 
Cross, C., \& Oppenheim, C. (2006). A genre analysis of scientific abstracts. Journal of Documentation 62(4), 428-46.

Dörnyei, Z. (2007). Research Methods in Applied Linguistics: Qualitative, Quantitative and Mixed Methodology. Oxford: Oxford University Press.

Dudley-Evans. T. (1986). Genre analysis: an investigation of the introduction and discussion sections of MSc. Dissertations. Dalam M. Coulthard (peny.) Talking about Text. Birmingham, U.K.: English Language Research, University of Birmingham.

Gopnik, M. (1972). Linguistic Structures in Scientific Texts. The Hague: Mouton.

Graetz, N. (1985). Teaching EFL students to extract information from abstracts. Dalam A.K. Pugh \& J.M. Ulijn (peny.) Reading for professional Purposes: Studies and Practices in Native and Foreign Languages. London: Heinemann Educational Books.

Hardjanto, T.D. (1997). Struktur wacana intisari artikel penelitian dalam jurnal ilmiah berbahasa Inggris. Humaniora V, 114-24.

Hill, S, B. Soppelsa \& G. West. (1982). Teaching ESL students to read and write experimental research paper. TESOL Quarterly 15/3: 33347.

Holmes, R. (1997). Genre analysis, and the social sciences: An investigation of the structure of research article discussion sections in three disciplines. English for Specific Purposes 16(4), 321-337.

Hyland, K. (2000). Disciplinary Discourses: Social Interactions in Academic Writing. Harlow: Pearson.

Jacks, G.V. (1964). The summary. Soils and Fertilizers 24, 409-11.

Kaplan, R. dkk. (1994). On abstract writing. Text 14(3), 401-26.

Landau, N. \& R.B. Weiss. (1976). Information Flow between Primary Journals and Secondary Services in the Biological Field. British Library Research and Development Report 5239, British Library Lending Division, Wetherby, West Yorkshire.

Lorés, R. (2004). On RA abstracts: From rhetorical structure to thematic organization. English for Specific Purposes, 23(3), 280-302.
May, R. (1997). The scientific wealth of nations. Science 275, hal. 793-96.

McKinlay, K. (1984). An Analysis of Discussion Sections in Medical Journal Articles. University of Birmingham, UK: Tesis Master. Tidak diterbitkan.

Pho, P. D. (2008). Research article abstracts in applied linguistics and educational technology: A study of linguistic realizations of rhetorical structure and authorial stance. Discourse Studies, 10(2), 231-50.

Pho, P. D. (2009). An evaluation of three different approaches to the analysis of research article abstracts. Monash University Linguistics Papers, 6(2), 11-16.

Pho, P.D. (2013). Authorial stance in research articles: Examples from applied linguistics and educational technology. New York: Palgrave Macmillan.

Samraj, B. (2014). Move Structure. Dalam Klaus P. Schneider \& Anne Barron (peny.) Pragmatics of Discourse. The Hague: de Gruyter, 385-406.

Santos, M.B.D. (1996). The textual organization of research paper abstracts in appliedlinguistic. Text 16(4), 481-99.

Swales, J. (1981). Aspects of article introductions. Aston ESP Research Report No. 1. Birmingham, U.K.: The University of Aston Language Studies Unit. (Mimeo.)

Swales, J. (1990). Genre Analysis: English in Academic and Research Settings. Cambridge: Cambridge University Press.

Swales, J. (2004). Research Genres: Explorations and Applications. Cambridge: Cambridge University Press.

Thomson Reuters. (2010). Web of Science Arts \& Humanities Citation Index. http://ip-science. thomsonreuters.com/mjl/wos_ahci_a5020_ final.pdf. Diakses 10 November 2010 .

Thomson Reuters. (2010). Web of Science Science Citation Index Expanded. http://ip-science. thomsonreuters.com/mjl/wos_scie_a5021_ final.pdf. Diakses 10 November 2010.

Thomson Reuters. (2010). Web of Science Social Sciences Citation Index. http://ip-science. thomsonreuters.com/mjl/ wos_ssci_a5022_ final.pdf. Diakses 10 November 2010.

Van Bonn, S., \& Swales, J. M. (2007). English and French journal abstracts in the language 
sciences: Three exploratory studies. English for Academic Purpose 6(2), 93-108.

Van Dijk, T.A. (1980). Macrostructures. Hillsdale, NJ: Lawrence Erlbaum.

Widdowson, H. (1983). Learning Purpose and Language
Use. Oxford: Oxford University Press.

Winter, E. (1986). Clause relations as information structure: Two basic text structures in English. In M. Coulthard (ed.) Talking about Text. Birmingham, UK: ELR, 88-108. 